\title{
Dietary sodium and arterial pressure: problems of studies within a single population
}

\author{
GRAHAM C M WATT AND CHRISTOPHER J W FOY \\ From the MRC Epidemiology and Medical Care Unit, Northwick Park Hospital, Harrow, Middlesex HA1 3UJ, \\ $U K$
}

SUMMARY The nature of the relationship between dietary sodium and arterial pressure remains uncertain, largely because of the difficulty of investigating this relationship within a single population. There are two main hypotheses: one requires that hypertensive and normotensive patients differ in their sodium intake, the other that they differ in their susceptibility to dietary sodium. Neither hypothesis has been fully explored. In this paper the types of study required to test each hypothesis are considered and published work is used to illustrate the problems of interpreting studies in this field.

The link between dietary sodium and arterial pressure is perhaps the most promising area for research into the cause of essential hypertension. Studies all over the world have consistently shown that in comparisons between populations high dietary sodium intakes are associated with high arterial pressures, progression with age, and high mortality from stroke, while diets containing under $50 \mathrm{mmol}$ of sodium $(3 \mathrm{~g}$ of $\mathrm{NaCl})$ a day are associated with low arterial pressures and no progression with age. ${ }^{12}$ The precise nature of the relationship between dietary sodium and arterial pressure remains unclear, ${ }^{34}$ largely because of the difficulty of investigating this relationship within a single population.

Two hypotheses could account for the association between dietary sodium and arterial pressure. ${ }^{5}$ The first hypothesis postulates that hypertensive patients take in and excrete more sodium than normotensive patients, while the second postulates that some individuals are more susceptible than others to the effect of a high sodium intake. The latter does not require that there is a difference in sodium intake between the two groups, only that mean intakes are high enough for "susceptible" individuals to develop high blood pressure. The evidence from studies between different populations suggest that this threshold level of intake would lie between 50 and $100 \mathrm{mmol}$ a day.

In studies between populations where mean sodium intake ranges from 10 to $400 \mathrm{mmol}$ a day relatively crude estimates of sodium intake may suffice, but in studies within populations where the range is much less more precise measures are required. Accordingly we have considered only those studies that measured sodium intake by collecting at least one 24-hour urine specimen from each subject. ${ }^{8}$

First hypothesis: hypertensive patients have a higher sodium intake than normotensive patients

This hypothesis can be formulated in two ways; either a general effect whereby anyone with a high sodium intake will develop high blood pressure or a specific effect whereby individuals genetically predisposed to high blood pressure have an increased avidity for sodium.

The hypothesis can be tested by measuring sodium intake and arterial pressure in a large number of individuals and calculating the regression or correlation coefficients. Owing to the pronounced variability of both measurements, such studies have to be very large if they are to detect a small association. For example, to detect a true regression slope of $0.1 \mathrm{~mm} \mathrm{Hg} / \mathrm{mmol} \mathrm{Na}$, significant at the $5 \%$ level with a $90 \%$ power, 5720 subjects would be needed if each provided only one 24-hour urine specimen. This calculation assumes standard deviations of $30 \mathrm{mmol}$ and $55 \mathrm{mmol}$ for betweenperson and within-person variation of daily sodium intake, ${ }^{7}$ and $16 \mathrm{~mm} \mathrm{Hg}$ for a single systolic blood pressure recording. ${ }^{8}$

The example is not chosen arbitrarily. A slope of $0.1 \mathrm{~mm} \mathrm{Hg} \mathrm{mmol} \mathrm{Na}$ corresponds to that found by Gleibermann ${ }^{2}$ in her review of sodium intake and arterial pressure in 27 different populations, and is the best available estimate of the strength of association to be expected within a single population. Parijs's finding that a 99-mmol reduction in sodium 
intake reduced systolic pressure by $7.7 \mathrm{~mm} \mathrm{Hg}$ provides further indirect evidence of an association of approximately this magnitude. ${ }^{9}$

Table 1 lists five studies of the regression of arterial pressure on sodium intake, with their calculated power values. ${ }^{10}$ (Another report by Watson et al ${ }^{11}$ in Mississippi could not be included; the published results, derived from four studies with different protocols, do not allow us to calculate a regression coefficient or a power value.) The table shows that three studies by Dawber et $a l^{12}$ at Framingham, Simpson et al $^{13}$ in New Zealand, and Ljungman et al ${ }^{14}$ in Sweden all found no association between dietary sodium and arterial pressure, but their power was insufficient to discount a slope of $0.1 \mathrm{~mm} \mathrm{Hg} / \mathrm{mmol} \mathrm{Na}$. Joossens et al ${ }^{15}$ in Belgium and Cooper $e a^{16}$ in Chicago did find an association at approximately this level. It is worth noting that the greater power of the Chicago study was obtained by collecting multiple 24-hour urine specimens from each subject, although the lower variability of blood pressure in children also contributed.

Joossens ${ }^{15}$ studied 1314 men (15\% over retirement age) who each provided one 24-hour urine specimen. Using his published data (which do not allow age to be taken into account) it can be calculated that this study found a regression slope of $0.4 \mathrm{~mm} \mathrm{Hg} / \mathrm{mmol} \mathrm{Na}$ between systolic pressure and urinary sodium corrected for creatinine. The men were divided into 20 groups ranked according to urinary sodium excretion, and group means were used in the analysis. The data handling in this study has been criticised, ${ }^{311} 16$ and it is misleading to say that $48 \%$ of the variance in systolic pressure is explained by the association with dietary sodium when much of the variation has been removed by the decision to analyse the data in groups. The correction of urinary sodium according to creatinine concentration is also of doubtful validity. ${ }^{6}$ These findings have not been corroborated in adults elsewhere, and no association was found with diastolic pressure, nor in the 713 women who took part in the same study.

Cooper ${ }^{16}$ found a significant association between mean individual sodium intake and systolic pressure in 73 children aged 11-14, who each provided seven consecutive 24-hour urine specimens. The results were standardised by multiple regression techniques for height, weight, pulse rate, age, sex, and race. The reported association is small- $0.06 \mathrm{~mm} \mathrm{Hg}$ $\mathrm{mmol} / \mathrm{Na}-$ but there are three reasons why a weak association may be important.

Firstly, differences in ranking within the blood pressure distribution are determined by relatively small differences in pressure at this age. This ranking may be related to the risk of developing high blood pressure in later life. ${ }^{17}$ Secondly, the mean daily sodium intake of these children $(133 \mathrm{mmol})$ greatly exceeded the physiological requirement for sodium (about $10 \mathrm{mmol}$ ), and possibly this level of intake corresponds to the flat part of a dose-response curve. Thirdly, if only certain individuals were susceptible to the effect of dietary sodium (see below) the observed association with blood pressure would be diluted by inclusion of many non-susceptible individuals.

The requirements of studies to show a regression slope between dietary sodium and arterial pressure are impossibly large for most investigators, and many have chosen instead to compare sodium intake in groups with high and low pressures. Since groups rather than individuals are being compared, this design is more practicable in terms of the number of subjects and 24-hour urine specimens required. To detect a 40-mmol difference in intake in either direction between two groups ( $5 \%$ significance level, $90 \%$ power), only 52 people are needed in each group, each subject providing one specimen. The figure of $40 \mathrm{mmol}$ is chosen arbitrarily but corresponds to about $25 \%$ of the range of sodium intake in adult Western populations.

Table 1 Studies to show a regression of blood pressure on $\mathrm{Na}$ excretion

\begin{tabular}{|c|c|c|c|c|c|}
\hline Authors & No of subjects & $\begin{array}{l}\text { No of 24-hour } \\
\text { urine specimens }\end{array}$ & $\begin{array}{l}\text { Pow } \\
\text { ( } \mathrm{mm} \\
0.1\end{array}$ & & Notes \\
\hline Cooper et al ${ }^{10}$ & 73 children aged $11-14$ & 7 & $\begin{array}{l}\% \\
85\end{array}$ & $\begin{array}{l}\% \\
99\end{array}$ & $\begin{array}{l}\text { Significant slope } \\
0.06 \mathrm{~mm} \mathrm{Hg} / \mathrm{mmol} \mathrm{Na}\end{array}$ \\
\hline Dawber et $a l^{12}$ & 297 men aged $40-49$ & 1 & 20 & 35 & No significant result \\
\hline Joossens et al ${ }^{1 s}$ & 1314 men & 1 & 36 & 87 & $\begin{array}{l}\text { Significant slope of } \\
\text { unstated value (see text) }\end{array}$ \\
\hline Joossens et al ${ }^{1 \mathrm{~s}}$ & 713 women & 1 & 28 & 62 & No significant result \\
\hline Ljungman et $a l^{14}$ & 120 men aged 49 & 3 & 26 & 55 & No significant result \\
\hline Simpson et al ${ }^{13}$ & 565 men & 1 & 25 & 52 & No significant result \\
\hline Simpson et $a l^{13}$ & 537 women & 1 & 25 & 52 & No significant result \\
\hline
\end{tabular}

All calculations are for systolic blood pressure. All studies had power over $95 \%$ to detect a slope of $0.5 \mathrm{~mm} \mathrm{Hg} / \mathrm{mmol} \mathrm{Na}$. 
This approach provides much less information than a regression study. Although it is a convenient method of detecting differences in sodium intake between hypertensive and normotensive groups, it does not tell us what proportion of the difference in pressure between the two groups can be attributed to the effect of dietary sodium. For this reason, the results of regression and comparative studies cannot be directly compared.

Table 2 lists nine studies comparing sodium intake in hypertensive and normotensive groups, with their calculated power values. ${ }^{18}$ It shows that only two studies, ${ }^{19}{ }^{20}$ both from Australia, found hypertensive patients to have a greater sodium intake than normotensive patients. The normotensive groups in both studies were small, however, and there is an apparent inconsistency between their mean sodium intake (111 and $118 \mathrm{mmol})$ and that of the normotensive group $(191 \mathrm{mmol})$ in another Australian study. ${ }^{32}$ The remaining comparative studies found no significant differences between the two groups, but while the power of several of these studies was large enough to exclude a difference of $40 \mathrm{mmol}$, none was large enough to exclude a difference of $20 \mathrm{mmol}$.

The apparent lack of any difference in sodium intake between these groups has to be interpreted with caution. The most useful negative result from this type of study comes when groups from top and bottom of the blood pressure distribution are being compared. In these studies "hypertensive" patients are being compared with "normotensive" patients, but when the latter category only means "not hypertensive," it can contain individuals from anywhere in the remaining $90-95 \%$ of the distribution of arterial pressure. The use of arbitrary cutting points to define hypertension can lead to further confusion when there is a wide scatter of ages in each group, since the cutting point will have a different meaning in young and old age groups. The absence of detailed information concerning the blood pressure data in most of these studies makes it difficult to interpret their negative results.

Dietary sodium could possibly have the same effect on arterial pressure in hypertensive and normotensive patients alike, the difference in pressure between them being caused by some other factor. No difference in sodium intake would then be expected.

\section{Second hypothesis: Hypertensive patients are more susceptible than normotensive patients to high sodium intake}

This hypothesis postulates that individuals vary in their susceptibility to dietary sodium, so that two people would respond differently to the same sodium intake, one becoming hypertensive, the other remaining normotensive. A test of this hypothesis would require two types of evidence. Firstly, there should be a demonstrable difference in sodium-handling between hypertensive and normotensive patients. Secondly, dietary intake should be known in both groups, to establish whether the differences in sodium-handling are independent of sodium intake.

Several studies have shown differences in sodium-handling between individuals. It is known that hypertensive patients ${ }^{22}$ and their offspring ${ }^{23}$ excrete intravenous sodium loads more quickly than normotensive patients. Several groups ${ }^{24-26}$ have found differences in sodium transport across red or white blood cell membranes in hypertensive patients

Table 2 Studies comparing sodium excretion in normotensive and hypertensive groups

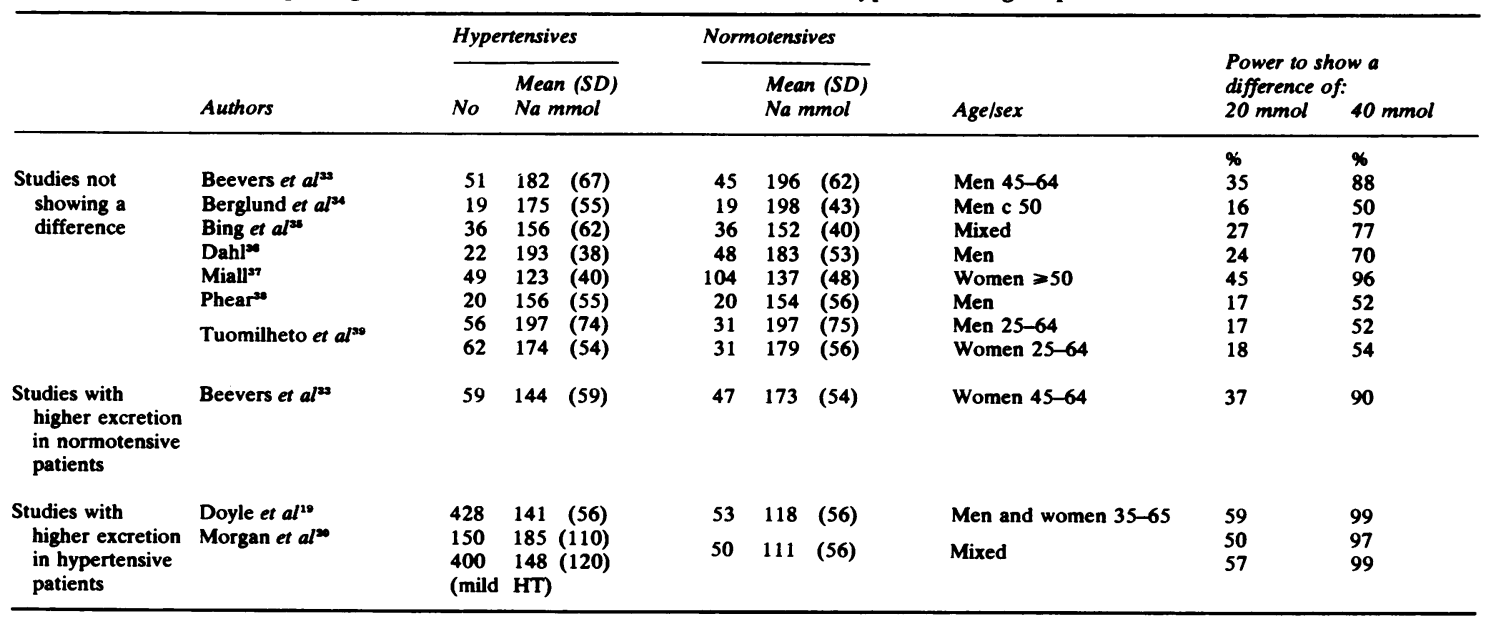


and their offspring. Poston $e t a^{27}$ found a circulating inhibitor of white cell sodium transport in hypertensive patients. None of these studies has included data on sodium intake, and we do not know to what extent the reported differences in sodium handling are related to variation in sodium intake, or to variation in susceptibility to dietary sodium.

\section{A COMBINED HYPOTHESIS}

The two hypotheses are not mutually exclusive. Although there may be no difference in sodium intake between "susceptible" and "non-susceptible" subjects, there could still be a direct relationship between sodium intake and arterial pressure within the susceptible group.

For example, Pietinen et $\mathbf{l}^{28}$ reported a regression slope of $0.07 \mathrm{~mm} \mathrm{Hg} / \mathrm{mmol} \mathrm{Na}(\mathrm{r}=0.7, \mathrm{p}<0.001)$ in the normotensive offspring of hypertensive parents, but no association in the offspring of normotensive parents. This study has been interpreted as showing evidence of genetic susceptibility to dietary sodium, but examination of the original paper leads to a more cautious conclusion. Fifty volunteers aged $20-40$ were divided into two groups of 21 and 29 on the basis of a family history of hypertension. Ignoring the small numbers, and the mixture of men and women, and blacks and whites, the major drawback of this study's design is that the family histories were not checked by blood pressure measurements in either group of parents. The result could also have been affected by differences in body weight between the two groups. ${ }^{29}$ This work needs to be repeated, preferably on offspring whose parents belong either both to the top or both to the bottom of the blood pressure distribution. These offspring differ in their familial risk of developing high blood pressure,$^{30}$ but only a small amount in their actual blood pressure levels. The differences between them may therefore be reasonably attributed to the pathogenesis of high blood pressure and not its secondary effects.

\section{Conclusions}

The clear association between dietary sodium and arterial pressure that exists in studies between different populations all but disappears when the focus is adjusted to the level of a single population. This may be entirely due to study design. Studies within a single population require a clear statement of the hypothesis under test, careful selection of an adequate number of subjects, and a valid measure of dietary sodium. Both dietary sodium and arterial pressure must be measured on a sufficiently large number of occasions. When studies that do not meet these criteria are excluded from consideration very few are left. The best of these ${ }^{16}$ found a small but significant association in children, and there is a need for further studies in this age group. There is no evidence of a strong linear relationship between dietary sodium and arterial pressure in adults, but the possibility of a weak association has not been excluded by studies of high quality. A slope of $0.1 \mathrm{~mm} \mathrm{Hg} / \mathrm{mmol} \mathrm{Na}$ seem small, but if a reduction of $50 \mathrm{mmol}$ in intake produced a fall in pressure of $5 \mathrm{~mm} \mathrm{Hg}$, this would be a worthwhile target both for patients with border-line hypertension wishing to avoid medication, and for the community as a whole ${ }^{31}$ It is interesting therefore to note the recent observation by MacGregor et $\boldsymbol{a l}^{32}$ that mean arterial pressure fell by $7.1 \mathrm{~mm} \mathrm{Hg}$ in mildly hypertensive patients who reduced their mean sodium intake by $76 \mathrm{mmol}$ a day.

In summary, the meagre evidence from single-population studies is consistent with the first hypothesis. Unfortunately, it falls a long way short of proof and only explains a small part of the range of arterial pressure.

The second hypothesis existed mainly as a theoretical consideration until the recent description of individual differences in sodium-handling at a cellular level. This hypothesis could explain a greater part of the range of arterial pressure, but the evidence is inconclusive at present. Little more can be said until population studies of sodium-handling also include data on dietary intake.

We wish to acknowledge comments made by $\operatorname{Dr} \mathrm{T} W$ Meade, Dr W E Miall, and Mr S G Thompson on an earlier draft of this paper.

Requests for reprints to: Dr G C M Watt, Glyncorrwg Health Centre, Near Port Talbot, West Glamorgan, SA13 3DP.

\section{References}

${ }^{1}$ Freis ED. Salt, volume and prevention of hypertension. Circulation 1976; 53: 589-95.

${ }^{2}$ Gleibermann L. Blood pressure and dietary salt in human populations. Ecology of Food and Nutrition 1973; 2: 143-56.

${ }^{3}$ Simpson FO. Salt and hypertension: a sceptical review of the evidence. Clinical Science 1979; 57: suppl 5: $463 \mathrm{~s}-80 \mathrm{~s}$.

4 Swales JD. Dietary salt and hypertension. Lancet 1980; i: 1177-9.

${ }^{5}$ Lever AF, Beretta-Piccoli C, Brown JJ, Davies DL, Fraser R, Robertson JIS. Sodium and potassium in essential hypertension. Br Med J 1981; 283: 463-8.

${ }^{6}$ Cummins RO, Shaper AG, Walker M. Methodological problems with estimation of salt intake. Lancet 1981; i: 1373-4. 
${ }^{7}$ Liu K, Cooper R, McKeever J, et al. Assessment of the association between habitual salt intake and high blood pressure: methodological problems. Am J Epidemiol 1979; 110: 219-26.

${ }^{8}$ Armitage P, Fox W, Rose GA, Tinker CM. The variability of measurements of casual blood pressure. II Survey experience. Clinical Science 1966; 30: 337-44.

${ }^{9}$ Parijs J, Joossens JV, Van der Linden L, Verstreken G, Amery AKPC. Moderate sodium restriction and diuretics in the treatment of hypertension. Am Heart $J$ 1973; 85: 22-34.

${ }^{10}$ Pearson ES, Hartley HO. Biometrika tables for staticians. Vol 2. London: Cambridge University Press, 1972: 66-74.

${ }^{11}$ Watson RL, Langford HG, Abernethy J, Barnes TY, Watson MJ. Urinary electrolytes, body weight, and blood pressure. Pooled cross-sectional results among four groups of adolescent females. Hypertension 1980; 2, suppl 1: 93-8.

${ }^{12}$ Dawber TR, Kannel WB, Kagan A, Donabedian RK, McNamara PN, Pearson G. Environmental factors in hypertension. In: Stamler J, Stamler R, Pullman TN, eds. The epidemiology of hypertension. New York: Grune and Stratton, 1967; 255-88.

${ }^{13}$ Simpson FO, Waal-Manning HJ, Bolli P, Phelan EL, Spears GFS. Relationship of blood pressure to sodium excretion in a population survey. Clin Sci Mol Med 1978 ; 55, suppl 4 : $373 s-5$ s.

${ }^{14}$ Ljungman S, Aurell M, Hartford M, Wikstrand J, Wilhelmsen L, Berglund G. Sodium excretion and blood pressure. Hypertension 1981; 3: 318-26.

${ }^{15}$ Joossens JV, Willems J, Claessens J, Claes J, Lissens W. Sodium and hypertension. In: Nutrition and cardiovascular disease. Proceedings of 7th International Meeting of Centro Studi Lipidi Alimentari Biologia e Clinica Della Nutrisione. Rimini: Fondazione Sasso, 1970: 91-110.

${ }^{16}$ Cooper R, Soltero I, Liu K, Berkson D, Levinson S, Stamler J. The association between urinary sodium excretion and blood pressure in children. Circulation 1980; 62: 97-104

${ }^{17}$ Szklo M. Epidemiological patterns of blood pressure in children. Epidemiol Rev 1979; 1: 143-69.

${ }^{18}$ Snedecor GW, Cochran WG. Statistical methods. 6th ed. Ames, Iowa: Iowa State University Press, 1967: 111-4.

${ }^{19}$ Doyle AE, Chua KG, Duffy S. Urinary sodium and creatinine excretion in hypertensive and normotensive Australians. Med J Aust 1976; 2: 898-900.

${ }^{20}$ Morgan T, Carney S, Wilson M. Interrelationship in humans between sodium intake and hypertension. Clin Exp Pharmacol Physiol 1975; suppl 2: 127-9.

${ }^{21}$ Morgan T, Adam W, Gillies A, Wilson M, Morgan G, Carney $S$. Hypertension treated by salt restriction. Lancet 1978; i: 227-30.

${ }^{22}$ Pedersen EB, Kornerup HJ. The renin-aldosterone system in exaggerated natriuresis of essential hypertension. Clin Sci Mol Med 1977; 53: 573-8.
${ }^{23}$ Wiggins RC, Basar I, Slater JDH. Effect of arterial pressure and inheritance on the sodium excretory capacity of normal young men. Clin Sci Mol Med 1978; 54: $639-47$.

${ }^{24}$ Meyer P, Garay RP, Nazaret C, et al. Inheritance of abnormal erythrocyte cation transport in essential hypertension. $\mathrm{Br}$ Med J 1981; 282: 1114-7.

${ }^{25}$ Woods KI, Beevers DG, West M. Familial abnormality of erythrocyte cation transport in essential hypertension. Br Med J 1981; 282: 1186-8.

${ }^{28}$ Edmonson RPS, MacGregor GA. Leucocyte cation transport in essential hypertension: its relation to the renin-angiotensin system. Br Med J 1981; 282: 1267-9.

${ }^{27}$ Poston L, Sewell RB, Wilkinson SP, et al. Evidence of a circulating sodium transport inhibitor in essential hypertension. Br Med J 1981; 282: 847-9.

${ }^{28}$ Pietinen PI, Wong O, Altschul AM. Electrolyte output, blood pressure and family history of hypertension. Am J Clin Nutr 1979; 32: 997-1005.

${ }^{29}$ Cooper R, Lui K. Correlations between salt intake, blood pressure and family history of hypertension. Am J Clin Nutr 1980; 33: 2218-20.

${ }^{30}$ Higgins MW, Keller JB, Metzner HL, Moore FE, Ostrander LD. Studies of blood pressure in Tecumseh, Michigan. II Antecedents in childhood of high blood pressure in young adults. Hypertension 1980; 2, suppl 1: 117-23.

${ }^{31}$ Rose GA. Strategy of prevention: lessons from cardiovascular disease. $\mathrm{Br} \mathrm{Med} J$ 1981; 282: 1847-51.

${ }^{32}$ MacGregor GA, Markandu MD, Best FE, et al. Double-blind randomised crossover trial of moderate sodium restriction in essential hypertension. Lancet 1982; i: $351-4$.

${ }^{33}$ Beevers DG, Hawthorne VM, Padfield PL. Salt and blood pressure in Scotland. Br Med J 1980; 281: 641-2.

${ }^{34}$ Berglund G, Wikstrand J, Wallentin I, Wilhelmsen L. Sodium excretion and sympathetic activity in relation to severity of hypertensive disease. Lancet 1976; i: 324-8.

${ }^{35}$ Bing RF, Thurston H, Swales JD. Salt intake and diuretic treatment of hypertension. Lancet 1979; ii: 121-3.

${ }^{36} \mathrm{Dahl}$ LK. Sodium intake of the American male: implications on the etiology of essential hypertension. Am J Clin Nutr 1958; 6: 1-7.

${ }^{37}$ Miall WE. Follow-up study of arterial pressure in the population of a Welsh mining valley. Br Med J 1959; ii: 1204-10.

${ }^{38}$ Phear DN. Salt intake and hypertension. Br Med J 1958; ii: 1453 .

${ }^{39}$ Tuomilheto J, Karppanen H, Tanskanen A, Tikkanen J, Vuori J. Sodium and potassium excretion in a sample of normotensive and hypertensive persons in eastern Finland. J Epidemiol Community Health 1980; 34: 174-8. 